\title{
Relationship between Forest Ecophysiology and Environment
}

\author{
Roberto Tognetti ${ }^{1,2, *(\mathbb{D})}$ and John D. Marshall ${ }^{3}$ (i) \\ 1 Department of Agricultural, Environmental and Food Sciences, University of Molise, \\ I-86100 Campobasso, CB, Italy \\ 2 Edmund Mach Foundation, EFI Project Center Mountain Forests (MOUNTFOR), \\ I-38010 San Michele All'Adige, TN, Italy \\ 3 Department of Forest Ecology and Management, Swedish University of Agricultural Sciences (SLU), \\ S-90183 Umeå, Sweden; john.marshall@slu.se \\ * Correspondence: tognetti@unimol.it; Tel.: +39-0874-404-735
}

Citation: Tognetti, R.; Marshall, J.D. Relationship between Forest Ecophysiology and Environment. Forests 2021, 12, 68. https://doi.org/ 10.3390/f12010068

Received: 2 January 2021

Accepted: 7 January 2021

Published: 9 January 2021

Publisher's Note: MDPI stays neutral with regard to jurisdictional clai$\mathrm{ms}$ in published maps and institutional affiliations.

Copyright: (C) 2021 by the authors. Licensee MDPI, Basel, Switzerland. This article is an open access article distributed under the terms and conditions of the Creative Commons Attribution (CC BY) license (https:// creativecommons.org/licenses/by/ $4.0 /)$.
Although aspects of forest ecophysiology and forest environments have received considerable attention from research scientists in the last three decades, assessment of implications for meeting the climate targets and international agreements is still a matter of debate. The goal of limiting the increase in global temperature gives forests a prominent role, mainly because they can be significant carbon sinks, capable of removing carbon dioxide from the atmosphere. However, in addition to serving as carbon sinks, forest plants suffer from the negative impacts of climate change. These negative impacts include chronic stress (e.g., drought stress), acute responses to strengthened disturbance events (e.g., windstorms), and long-term ecological processes (e.g., species shifts). Detecting how the intensification of disturbances and stresses will affect the trajectory of plant vulnerability and adaptive capacity to stress is a major scientific challenge, because forests provide a number of ecosystem services.

The impact of disturbances may exceed a threshold that defines undesirable effects on ecosystem processes and services. Understanding the mechanisms of resilience and tipping points in forest environments would guide better climate-smart management practices. This Special Issue explores recent advances in research on relationships between plant traits and the environment in forest ecosystems, as well as physiological thresholds associated with ecological changes.

Ecophysiological measurements are needed to reveal both subtle changes and abrupt deviations at appropriate spatial and temporal scales. Nevertheless, comparing static trait correlations does not provide sufficient information on the functional and structural acclimation potential of individual leaves to rapidly changing environmental conditions: this acclimation is especially notable for light, as Deguchi and Koyama observed in their experiment [1]. However, light affects the dynamics (i.e., production, growth, and death) of organs that, in turn, influence the crown environment. Variation in the light environment within the crown of tree saplings was shown to be affected by the redeployment of shoots and leaves by Koyama et al. [2], with differences between fast- and slow-growing species because of their distinct crown dynamics. These species differences can result in pronounced differences in plant carbon gain. Differences in carbon pools and fluxes were investigated by Diao et al. [3], in pure conifers vs. mixed broadleaves, through continuous monitoring of $\mathrm{CO}_{2}$ isotopes in situ. Not just the tree species (or forest type) but also the tree size mattered. Indeed, growing from seedlings in the understory to adult trees in the canopy layer required acclimation to different light environments along the way. This was illustrated by Deng et al. [4], who investigated leaf morphological and physiological traits across a vertical ambient light and tree height gradient in a tropical seasonal rainforest, highlighting the role of leaf functional traits in the adaptation to changing conditions during plant ontogeny.

In Mediterranean environments, water availability is the most important driver limiting tree growth and plant health. Szymczak et al. [5] used electronic dendrometers to 
analyze the responses of two native pine species to drought and precipitation events, observing different adaptation strategies to deal with the Mediterranean precipitation regime. Plants have developed different adaptation strategies to cope with abiotic stresses, and the response mechanism is regulated by multiple signaling pathways. Han et al. [6] examined transcription factors and their role in the interaction of these signaling pathways, particularly in response to cold and salt stress. Among functional traits, wood density is directly associated with mechanical support, carbon and nutrient storage, drought tolerance, water transport, and pathogen defense. Nelson et al. [7] tested whether canopy structure, climatic niche, geofloristic history, and habitat specialization related to wood density variation among members of a regional woody plant community in Mediterranean climatic conditions; their findings challenge classic assumptions about the adaptive significance of high wood density as a drought tolerance trait.

Increasing nitrogen deposition adds to warming temperature as a major driver, affecting the carbon sequestration potential, productivity, and water-use efficiency of forests. Giammarchi et al. [8] reported on long-term, manipulative experiments to improve the understanding of the carbon sequestration and mitigation ability of forests in response to increased nitrogen deposition. Atmospheric pollution (e.g., nitrogen oxides) adds to warming temperature in affecting plant metabolism and growth, the consequence being negative above certain thresholds. Wang et al. [9] fumigated leaves of an important agroforestry tree with nitrogen oxides and assessed the impact on nitrogen metabolism and photosynthetic efficiency, concluding that at a low concentration of fumigant, nitrogen oxides can be absorbed by leaves, protecting the photosynthetic apparatus and reducing the haze effect.

Regardless of environmental stress, forests are expected to deliver a number of functions and services, and mixed forests are considered more resistant to disturbances than pure stands. Russo et al. [10] found that mixed conifer and broadleaf forest stands had higher stand productivity and improved wood quality in comparison with corresponding monocultures, in a Mediterranean setting. In agroforestry systems, in addition to environmental disturbance, autotoxicity may strongly affect natural regeneration. Huang et al. [11] conducted an experiment on seedling growth, with different concentration gradients, using associated aqueous litter extracts, and concluded that autotoxicity inhibited seedling growth and natural regeneration of the studied tree species.

Warmer and drier environmental conditions will also affect future boreal and mountain forests, with an impact on photosynthetic rate and plant productivity. Ruiz-Pérez et al. [12] applied a mechanistic model of energy and mass transfer in the soil-plant-atmosphere continuum to explore the role of plant traits and projected environmental conditions on leaf temperature and photosynthetic rate, suggesting that trait selection should consider specifically the warmest period within the growing season. Understanding the responses of mature trees to global change is fundamental for predicting the potential or limitation of forest productivity. Liu et al. [13] used elevation gradients as proxy for changes in environmental factors to test whether the responses of carbon assimilation and nutrient allocation to environmental changes vary with tree ontogeny and leaf habit, noticing that young trees perform similarly to adult individuals. Stable isotope techniques provide insights into plant responses to environmental factors, notably leaf gas exchange and water use efficiency, though variation during plant development stages warrants further investigation. Li et al. [14] tested whether the $\delta^{13} \mathrm{C}$ and $\delta^{15} \mathrm{~N}$ signature changed with leaf or tree age in a mountain conifer and identified that leaf age compared to tree age plays a dominant role, with leaf nitrogen concentration also being an important determinant.

The effect of disturbance on reproductive biology is particularly critical for endangered plant species with small population size and low genetic diversity. Zhang et al. [15] conducted field fixed-point observations and laboratory experiments to study the reproductive system and seed germination of an endangered plant species with an extremely small population, in a tropical setting, concluding that this population can be expanded through indoor seedling breeding for salinity resistance. 
This Special Issue comprises a selection of papers reporting recent advances in research on relationships between plant functions and the environment. Natural settings, manipulated environments, and modeling exercises have been used to investigate abrupt deviations from the normal mode at diverse spatial and temporal scales. These reports offer insights into ecological dynamics and physiological responses to climatic perturbations and are useful to assess threshold-type relationships for tree decline and forest dieback, as well as to monitor consequences associated with ecological change. Integrating research results into innovative monitoring and decision-making may help forest managers to face climate change. We would like to thank all the authors and the reviewers of the papers published in this Special Issue for their great contributions and efforts. We are also grateful to the editorial board members and to the staff of the journal for their kind support in the preparation of this Special Issue.

Funding: R.T. and J.D.M. were supported by the Progetto bilaterale di Grande Rilevanza Italy-Sweden "Natural hazards in future forests: how to inform climate change adaptation" (MAECI) and the COST (European Cooperation in Science and Technology) Action CA15226 (Climate-Smart Forestry in Mountain Regions-CLIMO). J.D.M. was supported in part by the Knut and Alice Wallenberg Foundation (\#2015.0047).

Conflicts of Interest: The authors declare no conflict of interest.

\section{References}

1. Deguchi, R.; Koyama, K. Photosynthetic and Morphological Acclimation to High and Low Light Environments in Petasites japonicus subsp. giganteus. Forests 2020, 11, 1365. [CrossRef]

2. Koyama, K.; Shirakawa, H.; Kikuzawa, K. Redeployment of Shoots into Better-Lit Positions within the Crowns of Saplings of Five Species with Different Growth Patterns. Forests 2020, 11, 1301. [CrossRef]

3. Diao, H.; Wang, A.; Yuan, F.; Guan, D.; Dai, G.; Wu, J. Environmental Effects on Carbon Isotope Discrimination from Assimilation to Respiration in a Coniferous and Broad-Leaved Mixed Forest of Northeast China. Forests 2020, 11, 1156. [CrossRef]

4. Deng, Y.; Deng, X.; Dong, J.; Zhang, W.; Hu, T.; Nakamura, A.; Song, X.; Fu, P.; Cao, M. Detecting Growth Phase Shifts Based on Leaf Trait Variation of a Canopy Dipterocarp Tree Species (Parashorea chinensis). Forests 2020, 11, 1145. [CrossRef]

5. Szymczak, S.; Häusser, M.; Garel, E.; Santoni, S.; Huneau, F.; Knerr, I.; Trachte, K.; Bendix, J.; Bräuning, A. How Do Mediterranean Pine Trees Respond to Drought and Precipitation Events along an Elevation Gradient? Forests 2020, 11, 758. [CrossRef]

6. Han, D.; Han, J.; Yang, G.; Wang, S.; Xu, T.; Li, W. An ERF Transcription Factor Gene from Malus baccata (L.) Borkh, MbERF11, Affects Cold and Salt Stress Tolerance in Arabidopsis. Forests 2020, 11, 514. [CrossRef]

7. Nelson, R.A.; Francis, E.J.; Berry, J.A.; Cornwell, W.K.; Anderegg, L.D.L. The Role of Climate Niche, Geofloristic History, Habitat Preference, and Allometry on Wood Density within a California Plant Community. Forests 2020, 11, 105. [CrossRef]

8. Giammarchi, F.; Panzacchi, P.; Ventura, M.; Tonon, G. Tree Growth and Water-Use Efficiency Do Not React in the Short Term to Artificially Increased Nitrogen Deposition. Forests 2020, 11, 47. [CrossRef]

9. Wang, Y.; Jin, W.; Che, Y.; Huang, D.; Wang, J.; Zhao, M.; Sun, G. Atmospheric Nitrogen Dioxide Improves Photosynthesis in Mulberry Leaves via Effective Utilization of Excess Absorbed Light Energy. Forests 2019, 10, 312. [CrossRef]

10. Russo, D.; Marziliano, P.A.; Macrì, G.; Zimbalatti, G.; Tognetti, R.; Lombardi, F. Tree Growth and Wood Quality in Pure Vs. Mixed-Species Stands of European Beech and Calabrian Pine in Mediterranean Mountain Forests. Forests 2020, 11, 6. [CrossRef]

11. Huang, X.; Chen, J.; Liu, J.; Li, J.; Wu, M.; Tong, B. Autotoxicity Hinders the Natural Regeneration of Cinnamomum migao H. W. Li in Southwest China. Forests 2019, 10, 919. [CrossRef]

12. Ruiz-Pérez, G.; Launiainen, S.; Vico, G. Role of Plant Traits in Photosynthesis and Thermal Damage Avoidance under Warmer and Drier Climates in Boreal Forests. Forests 2019, 10, 398. [CrossRef]

13. Liu, J.-F.; Jiang, Z.-P.; Schaub, M.; Gessler, A.; Ni, Y.-Y.; Xiao, W.-F.; Li, M.-H. No Ontogenetic Shifts in C-, N- and P-Allocation for Two Distinct Tree Species along Elevational Gradients in the Swiss Alps. Forests 2019, 10, 394. [CrossRef]

14. Li, C.; Wang, B.; Chen, T.; Xu, G.; Wu, M.; Wu, G.; Wang, J. Leaf Age Compared to Tree Age Plays a Dominant Role in Leaf $\delta^{13} \mathrm{C}$ and $\delta^{15} \mathrm{~N}$ of Qinghai Spruce (Picea crassifolia Kom.). Forests 2019, 10, 310. [CrossRef]

15. Zhang, M.; Yang, X.; Long, W.; Li, D.; Lv, X. Reasons for the Extremely Small Population of putative hybrid Sonneratia $\times$ hainanensis W.C. Ko (Lythraceae). Forests 2019, 10, 526. [CrossRef] 